\title{
Glaucoma Medication Preferences among Glaucoma Specialists in Mexico
}

${ }_{1}^{1}$ Gabriel Lazcano-Gomez, ${ }^{2}$ Daniela Alvarez-Ascencio, ${ }^{3}$ Cindy Haro-Zuno, ${ }^{4}$ Mauricio Turati-Acosta
${ }^{5}$ Magdalena Garcia-Huerta, ${ }^{6}$ Jesus Jimenez-Arroyo, ${ }^{7}$ Rafael Castañeda-Diez, ${ }^{8}$ Armando Castillejos-Chevez
${ }^{9}$ Roberto Gonzalez-Salinas, ${ }^{10}$ Francisca Dominguez-Dueñas, ${ }^{11}$ Jesus Jimenez-Roman

\section{ABSTRACT}

Aim: To determine the glaucoma specialists' preferences for the different brands of topical glaucoma medications available in Mexico.

Materials and methods: A web-based survey was sent to 150 board-certified glaucoma specialists in Mexico, with 14 questions related to brand preferences for all glaucoma medications available in Mexico. Participants were asked to select each glaucoma medication class by brand and to state the factors leading to their choice.

Results: Data from $111(74 \%)$ glaucoma specialists were collected. Imot (timolol 0.5\%; Sophia, Mexico) was the preferred brand for the beta-blockers (BB) class by $71 \%(n=79)$ of the participants. Azopt (brinzolamide 1\%; Alcon Lab, US) was the preferred carbonic anhydrase inhibitor $(\mathrm{CAI})$ by $54 \%(\mathrm{n}=60)$ of the glaucoma specialists. Lumigan (bimatoprost $0.01 \%$ and $0.03 \%$; Allergan Inc., U.S.) was the first choice for the prostaglandin analogues (PGAs) in $62 \%(n=70)$ of the answers. The most frequently prescribed alpha-agonist (AA) was Agglad (brimonidine $0.2 \%$; Sophia Lab, Mexico) in 44\% $(n=49)$ of the answers. Medication accessibility (31\%), cost (29\%), and recommended dose (23\%) were the three main factors influencing the glaucoma specialists' preferences.

Conclusion: Medication cost and accessibility, as well as posology, remain the main factors influencing brand preferences among glaucoma doctors. In our professional opinion, the therapeutic effect must be the leading factor when prescribing topical medications in the daily practice, so that patients receive the best treatment option.

Clinical significance: This survey provides an understanding of the decision-making process when prescribing glaucoma medications by glaucoma specialists in a Latin American developing country. Ideally, patient treatment should be individualized and aimed to achieve the best results possible for their specific condition.

\footnotetext{
${ }^{1,5-8}$ Associate Professor, ${ }^{2,3}$ Fellow, ${ }^{4}$ Professor, ${ }^{9}$ Associate Researcher, ${ }^{10,11}$ Head

${ }^{1-8,11}$ Department of Glaucoma, Association to Avoid Blindness in Mexico, IAP, Mexico City, Mexico

${ }^{9}$ Department of Biomedical Research, University of Queretaro Queretaro, Mexico

${ }^{10}$ Department of Glaucoma, National Institute of Rehabilitation Mexico City, Mexico

Corresponding Author: Daniela Alvarez-Ascencio, Fellow Alfredo de Musset 310-208, Polanco, Miguel Hidalgo, Mexico City, Mexico 11550, Phone: +5215541425489, e-mail: alvarezdann@gmail.com
}

Keywords: Brands, Generic, Glaucoma medications, Preferences, Survey.

How to cite this article: Lazcano-Gomez G, Alvarez-Ascencio D, Haro-Zuno C, Turati-Acosta M, Garcia-Huerta M, JimenezArroyo J, Castañeda-Diez R, Castillejos-Chevez A, GonzalezSalinas R, Dominguez-Dueñas F, Jimenez-Roman J. Glaucoma Medication Preferences among Glaucoma Specialists in Mexico. J Curr Glaucoma Pract 2017;11(3):97-100.

\section{Source of support: Nil}

Conflict of interest: None

\section{INTRODUCTION}

Glaucoma is the leading cause of irreversible blindness worldwide. ${ }^{1}$ It is a chronic and progressive disease, which to this day has only one modifiable risk factor, lowering the intraocular pressure (IOP). This has been shown to slow or halt the progression of the optic nerve (ON) degeneration. ${ }^{2}$ Even though a number of treatment options (lasers and novel surgical techniques) have been developed, topical medications remain the first-line therapy for glaucoma in the majority of cases.,

Currently, the pharmaceutical market provides physicians with a broad spectrum of brands for each class of glaucoma medications. Brands can differ not only in price, but also in posology, preservative, and bottle design, which may affect treatment outcomes. Even though the therapeutic effect should be the main reason when prescribing specific brands, ${ }^{5,6}$ physicians' preferences for certain brands are also determined by the drug availability, cost, patient's preference, and insurance coverage, and in some cases are influenced by the exposure to the pharmaceutical companies. $^{7}$

Many regulations have been developed to prevent the risks and avoid doctors' exposure to certain pharmaceutical company influences. These regulations have benefited both doctors and patients, in reducing the number of malpractice lawsuits and misconducts by the medical and pharmaceutical community. ${ }^{8}$

There has not been a descriptive review of brand preferences among glaucoma specialists in Latin America, which has a population with high incidence of open-angle glaucoma (OAG). ${ }^{9}$ This study aims to determine the preferences of glaucoma specialists for the different brands 
of all topical glaucoma medications available in Mexico, and it was conducted from May to June 2016.

\section{MATERIALS AND METHODS}

This cross-sectional study was approved by the Internal Review Board of the "Asociación Para Evitar la Ceguera en México" Hospital. We created a web-based questionnaire (SurveyMonkey ${ }^{\circledR}$ ), with 14 questions related to brand preferences for all the glaucoma medications available in Mexico. The survey was delivered to 150 board-certified glaucoma specialists in Mexico using the "Mexican Ophthalmology Society" database and with the authorization of the "Mexican College of Glaucoma." The survey did not include any personal information to maintain the confidentiality of the study participants.

The survey included all the glaucoma medications available on the Mexican pharmaceutical market, including generic medications. All available brands were categorized by (1) glaucoma medication class: BB, CAIs, PGAs, and AAs; and (2) fixed combination drug type: Double fixed combination and triple fixed combination. The participants were asked to choose their preferred brand for each medication class and type. Assessment of the factors influencing their preferences, such as cost, availability, bottle design, insurance, recommended dose, personal preference, and relationship with the pharmaceutical company, was also included.

Data were collected using the same online program and statistical analyses were performed using SAS software version 9.4 (SAS Institute Inc, Cary, NC).

\section{RESULTS}

Data from 111 (74\%) glaucoma specialists were collected. Imot (timolol 0.5\%; Sophia Laboratories, Guadalajara,

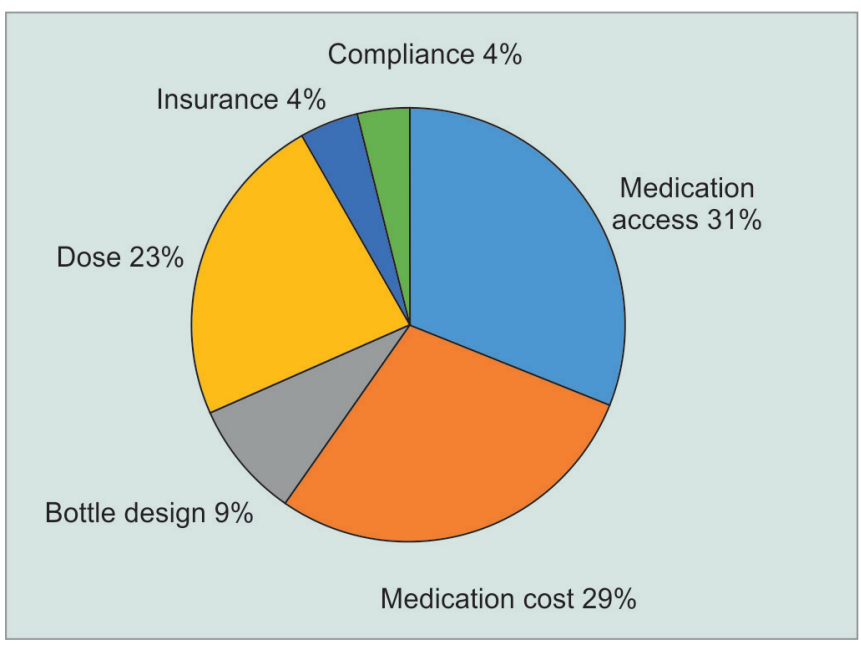

Graph 1: Factors leading to medication choice

Mexico) was the preferred brand for BB by $71 \%(n=79)$ of the participants. Azopt (brinzolamide 1\%; Alcon Lab, U.S.) was the preferred CAI by $54 \%(n=60)$ of the cases. Lumigan (bimatoprost 0.01\% and 0.03\%; Allergan Inc., U.S.) was the first choice for the PGAs in $62 \%(n=70)$ of the answers. The most frequently prescribed AA was Agglad (brimonidine 0.2\%; Sophia Lab, Mexico) in 44\% $(\mathrm{n}=49)$ of the answers. Combigan-D (timolol $0.2 \%$ / brimonidine $0.5 \%$; Allergan Inc., U.S.) and Krytantek (timolol $0.5 \%$ /dorzolamide $2 \%$ /brimonidine $0.2 \%$; Sophia Lab, Mexico) were the preferred fixed combinations by $100 \%(n=111)$ of the physicians. Commercial brands were preferred over generics for all glaucoma medications. The preferences for each brand are shown in Graph 1. Medication access $(31 \%, n=64)$, cost $(29 \%$, $n=59)$, and recommended dose $(23 \%, n=48)$ were the three main factors influencing the preferences. The factors that lead to the choice of each brand are shown in Graph 2.

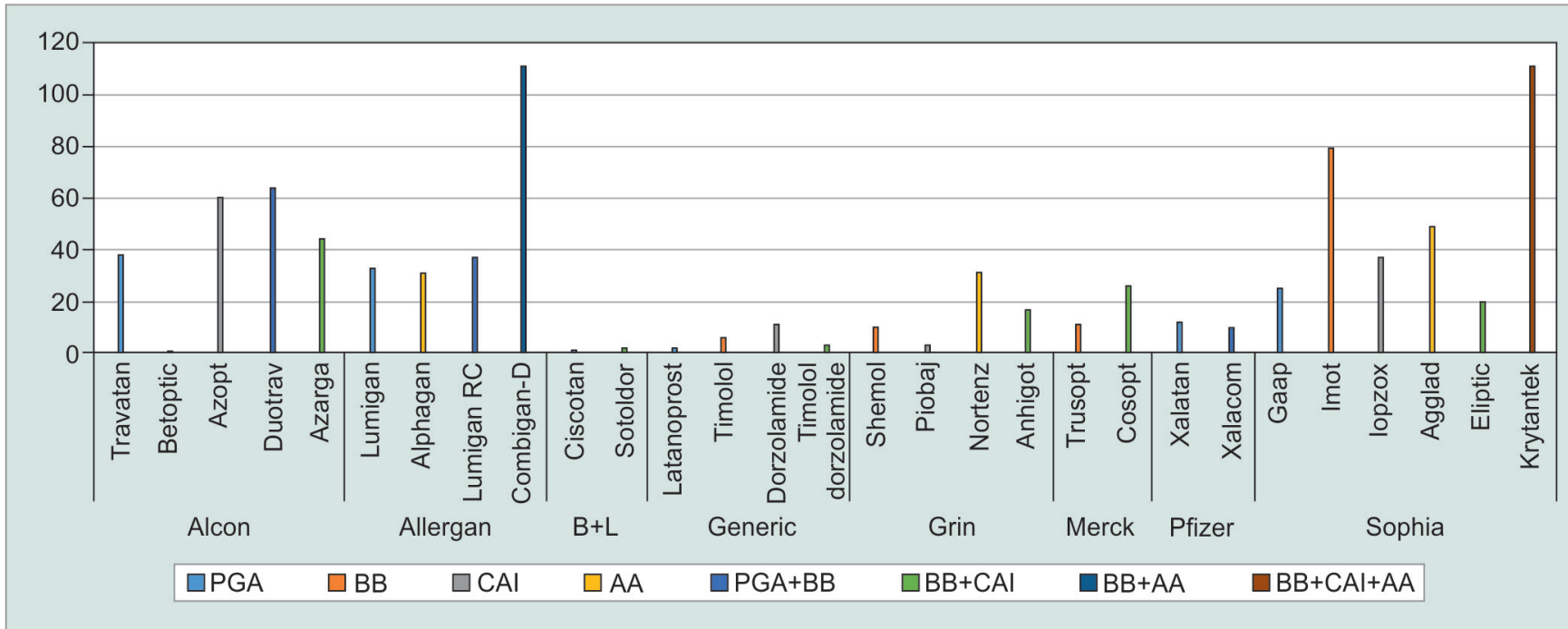

Graph 2: Glaucoma medication preferences by type and brand 


\section{DISCUSSION}

As previously described, Alcon Laboratories (Fort Worth, Texas, US) and Sophia Laboratories (Guadalajara, Mexico) lead the glaucoma drugs market in Mexico. Lumigan (bimatoprost $0.01 \%$ and $0.03 \%$; Allergan Inc., U.S.), Agglad (brimonidine 0.2\%; Sophia Lab, Mexico), and Duotrav (travoprost 0.004\%/timolol 0.5\%; Alcon Lab, US) were selected as the first option when prescribing PGA, AA, and a double fixed combination of PGA+BB respectively, in this study. Imot (timolol 0.5\%; Sophia Lab, Mexico), Azarga (brinzolamide 1\%/timolol 0.5\%; Alcon Lab, US), and Krytantek (timolol 0.5\%/dorzolamide 2\%/ brimonidine $0.2 \%$; Sophia Lab, Mexico) were selected as the first option when prescribing $\mathrm{BB}, \mathrm{BB}+\mathrm{CAI}$, and a triple fixed combination of $\mathrm{BB}+\mathrm{CAI}+\mathrm{AA}$. Krytantek is the only triple fixed combination available in the Mexican pharmaceutical market.

Access to the medications remains an important issue when prescribing them in the developing countries. The availability of certain drugs may not be widespread through all the regions and could lead to difficulties with treatment compliance. ${ }^{10}$ Medication cost is also one of the leading factors, influencing physicians' preferences, especially in countries like Mexico, where most patients do not have health insurance. ${ }^{11}$ Even though $30 \%$ of the physicians considered the cost to be the most important factor when prescribing a medication, the preferred brands in this study were the most expensive options available, as reported in our previous study on the glaucoma therapy cost in Mexico. ${ }^{5}$

Pharmaceutical companies use marketing strategies in order to influence physicians' choices when prescribing medications; ${ }^{12}$ the more expensive the strategies are the more effective they become. ${ }^{13}$ Other influencing factors include good rapport with the pharmaceutical company representatives, company's reputation, promotional materials, gifts, and other incentives. ${ }^{14,15}$

Product quality and therapeutic effect still need to be the main reason to prescribe a medication of any kind, regardless of the strategies used to promote drugs. ${ }^{16}$

Generic drugs were preferred as the first therapeutic option for glaucoma patients in only $19 \%$ of the participants $(n=22)$, showing that general skepticism related to generic medications is still common. Prescribing generic drugs continues to be an underused strategy that has the potential to increase value of care, reduce health care costs, and improve medication adherence and, ultimately, clinical results especially in developing countries. ${ }^{17}$ Unfortunately, unlike their brand-name counterparts, generic drugs are not marketed, leaving physicians to learn about them from colleagues, literature, pharmaceutical representatives, and/or patients themselves. ${ }^{18,19}$
Collecting research data from a web-based survey has certain limitations when analyzing the results. This survey was directed only to board-certified glaucoma specialists, but since noncertified glaucoma specialists and general ophthalmologists can also prescribe glaucoma medications, the overall preferences of the Mexican ophthalmologists for glaucoma medications available in Mexico may not be reflected in the results of this study.

\section{CONCLUSION}

Many factors play a role in the prescription preferences and patterns by glaucoma specialists. Even though pharmaceutical marketing can have positive effects regarding medical prescriptions, physicians should be aware of direct and indirect influences on their practice and therapeutic decisions. Medication cost and accessibility, as well as posology, remain the main factors influencing brand preferences among doctors. Based on our professional opinion, the therapeutic effect must be the leading factor when prescribing medications in the daily practice, so that patients receive the best treatment modality for their diseases. The results reported in this study demonstrate that although in a small percentage, many factors, such as pharmaceutical marketing strategies and compliance with pharmaceuticals, continue to play an important role when deciding which brand should be prescribed for glaucoma patients.

\section{CLINICAL SIGNIFICANCE}

This survey provides an understanding on the decisionmaking process when prescribing glaucoma medications by specialists in a Latin American developing country. Ideally, patient treatment should be individualized and aimed to achieve the best results possible for their specific condition.

\section{ACKNOWLEDGMENT}

Authors would like to thank Dr Mina Pantcheva, University of Colorado for the guidance and kind support.

\section{REFERENCES}

1. Shaaraw TM, Hitchings RA, Crowston JG, Sherwood MB. Glaucoma: Elsevier Health Sciences; 2009. 1348p.

2. Cook C, Foster P. Epidemiology of glaucoma: what's new? Can J Ophthalmol 2012 Jun;47(3):223-226.

3. Marquis RE, Whitson JT. Management of glaucoma: focus on pharmacological therapy. Drugs Aging 2005;22(1):1-21.

4. McAlinden C. Selective laser trabeculoplasty (SLT) vs other treatment modalities for glaucoma: systematic review. Eye (Lond) 2014 Mar;28(3):249-258.

5. Lazcano-Gomez G,Hernandez-Oteyza A, Iriarte-Barbosa MJ, Hernandez-Garciadiego C. Topical glaucoma therapy cost in Mexico. Int Ophthalmol 2014 Apr;34(2):241-249. 
6. Schlenker MB, Trope GE, Buys YM. Comparison of United States and Canadian glaucoma medication costs and price change from 2006 to 2013. J Ophthalmol 2015;2015:547960.

7. Heikkilä R, Mäntyselkä P, Ahonen R. Price, familiarity, and availability determine the choice of drug - a populationbased survey five years after generic substitution was introduced in Finland. BMC Clin Pharmacol 2011 Dec 15;11:20.

8. Duke EM. OIG Compliance Program Guidance for Pharmaceutical Manufacturers. Federal Register 2003 May 5;68(86). Available from: http://oig.hhs.gov/authorities/ docs/03/050503FRCPGPharmac.pdf.

9. Varma R, Wang D, Wu C, Francis BA, Nguyen BB, Chopra V, Memarzadeh F, Torres M, Azen SP, Los Angeles Latino Eye Study Group. Four-year incidence of open-angle glaucoma and ocular hypertension: the Los Angeles Latino Eye Study. Am J Ophthalmol 2012 Aug;154(2):315-325.

10. Wirtz VJ, Russo G, Kageyama-Escobar Mde L. Access to medicines by ambulatory health service users in Mexico: an analysis of the national health surveys 1994 to 2006. Salud Publica Mex 2010 Jan-Feb;52(1):30-38.

11. Puentes-Rosas E, Sesma S, Gómez-Dantés O. Estimación de la población con seguro de salud en México mediante una encuesta nacional. Salud Publica Mex 2005;47 (Suppl 1):S22-S26.

12. Alpern JD, Song J, Stauffer WM. Essential medicines in the United States - why access is diminishing. N Engl J Med 2016 May 19;374(20):1904-1907.
13. Narendran R, Narendranathan M. Influence of pharmaceutical marketing on prescription practices of physicians. J Indian Med Assoc 2013 Jan;111(1):47-50.

14. Lieb K, Brandtönies S. A survey of German physicians in private practice about contacts with pharmaceutical sales representatives. Dtsch Arztebl Int 2010 Jun;107(22):392-398.

15. Alssageer MA, Kowalski SR. What do Libyan doctors perceive as the benefits, ethical issues and influences of their interactions with pharmaceutical company representatives? Pan Afr Med J 2013 Apr 6;14:132.

16. Randall ML, Rosenbaum JR, Rohrbaugh RM, Rosenheck RA. Attitudes and behaviors of psychiatry residents toward pharmaceutical representatives before and after an educational intervention. Acad Psychiatry 2005;29(1):33-39.

17. Chee M, Ngooi S, Arora VM. Prescription trends-brandname drugs vs generic. JAMA Intern Med 2016 Oct 1;176(10): 1573-1574.

18. Kesselheim AS, Gagne JJ, Eddings W, Franklin JM, Ross KM, Fulchino LA, Campbell EG. Prevalence and predictors of generic drug skepticism among physicians: results of a national survey. JAMA Intern Med 2016 Jun 1;176(6): 845-847.

19. Kyle GJ, Nissen LM, Tett SE. Pharmaceutical company influences on medication prescribing and their potential impact on quality use of medicines. J Clin Pharm Ther 2008 Oct;33(5):553-559. 